\title{
MAKNA DAN FUNGSIINSKRIPSI PADA MAKAM LAJANGIRU DI BONTOALA MAKASSAR (Study Arkeo-epigrafi) \\ Meaning andfunction of the inscription in Lajangiru Cemetery Bontoala Makassar (a study arkeo-epigraphy)
}

\author{
Oleh: Muhammad Zubair* \\ *Peneliti pada Balai Penelitian dan Pengembangan Agama Makassar \\ Kantor: Jl. A.P. Pettarani No. 72 Makassar \\ E-mail: ingatbair@gmail.com
}

\begin{abstract}
Abstrak
Penelitian ini berangkat dari asumsi adanya pase sejarah yang penting pada masa perkembangan Islam di Makassar yang terpendam bersama berlalunya masa tersebut, sehingga untuk mengungkap kembali sejarah tersebut dibutuhkan suatu instrumen faktual yang dapat diteliti secara ilmiah dan menjadi pembuktian sejarah tersebut. Penelitian dilakukan melalui inskripsiyang terdapatpada makam Lajangiru Bontoala Makassar, dengan menggunakan metode penelitian deskriptif analitis, pada kompleks makam yang terdiri dari 233 buah makam ditemukan adanya sebanyak 45 buah makam yang berusia 50 tahun ke atas, tujuh buah inskripsi yang dapat dibaca adalah; I) Ladjangiroe HAbd Madjid Wafat 22 Mar 193, 2) M.Said Attamimi Wafat'5 Agustus 1950, 3) / J L $£ / V 8 \mathrm{i} \wedge^{\wedge} \wedge>\&$ A' $5^{\circ} \quad \%>V^{\prime} \circ 16$ ^ $\mathbf{V} /{ }^{*} \mathbf{Y} 13401811 \quad 1921$ Afey ft A $\quad$ (Abd'.Wadud, Ime paranakeng namate kemmisi 16 bulan $134018 \quad 11 \quad 1921$ umuruna 78 t'aung), 4) Soelaeman Bin Mahmoed Meninggal 1/1/21-1339H, 5) H.Muchtar Luthfi Wafat Pada Peristiwa 5 Agustus 1950, 6) Inskripsi Makam Habib Imam Ali bin Abdurrahman bin Ali bin Syihab 29 Rabi'I Tsani 1333 H/16 Maret 1915 M., 7) Inskripsi Yunus bin Ali Afandi Tahun 1335 H/ 1916 M. Inskripsi tersebut dimaksudkan sebagai penghormatan bagi mereka atas iasanya dalam menyebarkan ajaran Islam pada masa pemerintahan "I Makkulau Daeng Serang Karaeng Lembangparang Sultan Husain Tuminang ri Bundu'na", Raja Gowa 1895-1906.
\end{abstract}

Kata Kunci: Makam, Inskripsi Makam

\section{Abstract}

This study departs from the assumption of an important historical era in the development of Islam in Makassar buried with the passing of time, so to reveal back the history factually needed an instrument that can be studied scientifically and become the historical evidence. Research conducted through the inscriptions found in the graves of Bontoala Lajangiru Makassar, thpse nre- 1) Ladianeiroe HAbdMadiid Wafat 22 Mar

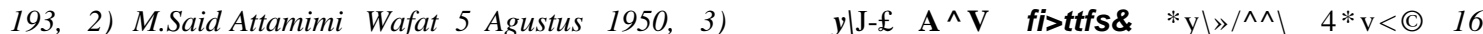
£ $\boldsymbol{\$} \$ \mathbf{V} \boldsymbol{A} \& \boldsymbol{x t} 134018111921 \mathrm{M} \mathrm{V} \mathrm{f} \mathrm{t} \mathrm{A} 78 \mathrm{~A} \quad$ (Abd. Wadud, Ime paranakeng namate kemmisi 16 bulan $13401811 \quad 1921$ umuruna 78ta'ung), 4) Soelaman Bin Mahmoed die 1/1/21-1339H, 5) H.Muchtar Luthfi pass away at event 5 augusts 1950, 6) Inskripsi Makam Habib Imam Ali bin Abdurrahman bin Ali bin Syihab 29 Rabi'I Tsani 1333 H/16 Maret 1915 M., 7) Inskripsi Yunus bin Ali Afandi Tahun 1335 H/1916 M. These inscriptions was intended as a tribute for their dedication in spreading islamic teaching in the reign of Sultan Husain Tuminang ri Bundu'na, king of Gowa 1895-1906.

Key Word: Tomb, inscription of tomb

PENDAHULUAN

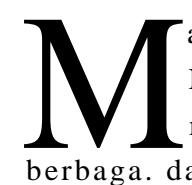

asuknya Islam penduduk pribumi Nusantara serta terbentuknya pemerintahan-pemerintahan Islam di a. daerah kepulauan in., membawa arus perdagangan dengan kaum Mushmin dari pusat dunia Islam menjadi semakin erat. Orang Arab yang bermigras. ke Nusantara juga semakin banyak. Yang terbesar d.antaranya adalah berasal dari Hadramaut, Yaman. Dalam Tarikh
Hadramaut, migrasi ini bahkan dikatakan sebagai yang terbesar sepanjang sejarah Hadramaut. Namun setelah bangsa-bangsa EropaNasrani berdatangan dan dengan rakusnya ${ }^{\text {m }}$ TMS $^{\text {TMTM }} i$ daerah-demi daerah di Nusantara, ииьтм $\S$ an dengan pusat dun.a Islam seakan

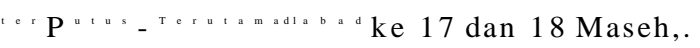
Penyebabnya, selain karena kaum Mushmin Nus.... disibukkan oleh perlawanan menentang penjajahan, juga karena berbagai peraturan yang diciptakan oleh kaum kolomahs.

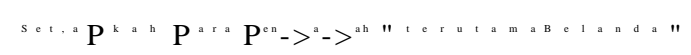
menundukkan kerajaan Islam di Nusantara, 
mereka pasti menyodorkan perjanjian yang isinya melarang kerajaan tersebut berhubungan dagang dengan dunia luar kecuali melalui mereka. Maka terputuslah hubungan ummat Islam Nusantara dengan ummat Islam dari bangsa-bangsa lain yangtelah terjalin beratus-ratus tahun.

Salah satu bukti adanya kedatangan orang Arab pada masa itu adalah dengan ditemukannya makammakam atau kompleks makam orang Arab yang diketahui oleh masyarakat sekitarnya atau yang dapat dikenal melalui inskripsi yang tertulis pada makamnya. Di Sulawesi Selatan terdapat sebuah situs berupa komplek makam yang disebut makam Lajangiru di Kecamatan Bontoala Makassar, di sini terdapat lima makam besar yang bangunannya berbentuk kubah masj id, mereka yang dimakamkan di sini adalah peny iar Agama Islam ratusan tahun silam, masyarakat setempat sering menyebut tempat ini sebagai pemakaman orang Arab yang berdasarkan informasi turun-temurun menyatakan bahwa pema-kaman ini merupakan kompleks pemakaman orang Arab, penelitian lebih lanjut tentang keberadaan makam ini belum pernah dipublikasikan dan karena itulah penulis beraksud menelitinya.

Makam Lajangiru di Bontoala Makassar yang sering juga disebut dengan "makam orang Arab" merupakan salah satu situs yang memendam banyak misteri. Karena itulah penelitian arkeo-epigrafi tentang inskripsi pada makam tersebut dilaksanakan untuk mengungkap isi, klasifikasi, makna dan fungsinya, di mana dengan mengungkap inskripsi yang ada pada makam tersebut diharapkan dapat memberikan informasi tentang corak perkembangan Islam di Makassar pada masa lalu.

1. Apa isi inskripsi yang ada pada makam Lajangiru di Bontoala Makassar?

2. Bagaimana klasifikasi inskripsi yang ada dalam kompleks makam tersebut?

3. Apa makna dan fungsi inskripsi tersebut?

4. Bagaimana peranan tokoh pada yang dimakamkan tersebut?

Penelitian ini bertujuan untuk:

a. Mengungkapkan isi inskripsi makam Lajangiru di Bontoala Makassar. b. Mengklasifikasi inskripsi yang ada pada Makam Lajangiru di Bontoala Makassar.

c. Mengungkap makna dan fungsi isnkripsi pada makam tersebut sebagai media syiar Islam di Makassar.

d. Mengungkapkan peranan tokoh yang di makamkan pada makam tersebut.

Adapun manfaat penelitian ini yaitu:

a. Manfaat Ilmiah

Penelitian ini diharapkan mengungkap fakta baru tentang sejarah Islam sebagai sumbangan pemikiran dan kontribusi terhadap penelitian dan kajian sejarah Islam di Indonesia khususnya tentang masyarakat Makassar di Sulawesi Selatan.

b. Manfaat Praktis

Penelitian ini diharapkan menjadi masukan atau dasar dalam pengambilan kebijakan oleh para pengelola dan pengambil kebijakan baik dari pihak Pemerintah maupun masyarakat. Agar memberikan perhatian terhadap benda-benda peninggalan masyarakat lampau sebagai warisan budaya bangsa Indonesia.

Dalam kajian epigrafi, Poerbatjaraka dikenal sangat banyak meneliti yang berkenaan dengan beberapa prasasti yang dianggap penting serta masih menyimpan sejumlah permasalahan. Prasasti-prasasti yang dibahas antara lain adalah pembacaan ulang terhadap prasasti Batu Tulis di Bogor. Prasasti ini telah dikaji oleh para ahli peminat Sunda Kuna, misalnya Frederich, K.F.Holle, C.M.Pleyte, dan Hoesein Djajadiningrat. Poerbatjaraka berhasil melakukan pembacaan secara lebih baik, serta sumbangan kajiannya yang penting adalah berhasil menafsirkan secara tepat kronologi prasasti itu yang menurutny candrasangkala itu seharusnya berbunyi "panes pandawa nge(m)ban bumi" dengan nilai angka $1255 \mathrm{~S}$ (1355 M) (Sutaarga 1965:25-6). Prasasti lainnyayan dibahas oleh Poerbatjaraka adalah yang dipahatka pada asana area Aksobhya di Simpang Surabay Walaupun prasasti tersebut sudah dibahas oleh H.Ke Poerbatjaraka berhasil membacanya kembali dengan sempurna, tafsiran yang dikemukakannya bahwa 
prasasti ini disusun oleh Nada, ayah Mpu Prapanca, - aiaupun prasasti ini bertarikh 1211 S, namun baru xsrtulis sesudah tahun $1272 \mathrm{~S}$, demikian menurut - rerbatjaraka ${ }^{2}$. Kajian epigrafi lainnya yang : akukan oleh Poerbatjaraka adalah terhadap rr-isasti Balaw (tahun $1227 \mathrm{~S}$ ) dan Sukamerta (tahun $1218 \mathrm{~S})$.

Adapun penelitian tentang makam di Sulawesi Sefatan setidaknya telah dilakukan oleh beberapa rt-.eliti sebagai berikut:

Abd. Muttalib: meneliti makam kuno di Sulawesi Selatan dengan mengkaji ragam pola pemakaman zi-ian prasejarah, mezolitikum, megalitikum, masa re-jndagian sampai pada masa pola pemakaman $\wedge$ belum datangnya agama Islam di Sulawesi Nrlatan.

Muhaeminah; meneliti situs makam kuna Islam $£$ Soppeng, dengan menitik beratkan pembahasannya ia«da aspek pola makam Islam yang ada pada makam i. a-raja di Kerajaan Soppeng yang dikaitkan dengan tc 2ta sosial masyarakatnya.

Muhaeminah; melakukan sulrvei arkeologi tentang Minm-makam kuna di situs Barrang Lompo dengan embahas tipologi makam dalam bentuk deskripsi junum.

Dalam pencarian literatur tentang penelitian $\sim$ jvripsi makam yang ada di Sulawesi Selatan, tidak : :emukan adanya pembahasan tentang kompleks nakam Lajangiru, namun setelah melakukan penelitian -irangan diketahui bahwa kompleks makam ini telah nteliti oleh seorang mahasiswaUniversitas Hasanuddin, :i--nun penelitian tersebut berfokus dalam aspek - \eologis dan tidak mengkaji tentang inskripsi yang id pada makam.

Salah satu hasil cukup menonjol dari budaya In: esia masa Islam adalah tipologi dan nisan makam. ;?agai hasil seni rupa Indonesia, dari segi arsitektur :.ir filsafat, unsur-unsur pokok dari nisan-nisan di In::nesia merupakan satu kelanjutan dari masa-masa cTdumnya yakni masa prasejarah yang disambung masa Hindu dan Islam. Nisan kubur lebih dikenal -'.-an istilah makam. Pengertian makam di sini adalah suatu si stem penguburan untuk orang muslim, dimana di atas permukaan tanah dari tokoh yang dikuburkan biasanya dibuat bangunan yang pada umumnya persegi panjang dengan terletak arah terletak arah UtaraSelatan. Dalam makam ini sering ditampilkan ragam hias dengan pola-pola tertentu.

Dilihat dari sudut ilmu bangunan, makam memiliki tiga unsur yang menjadi kelengkapan satu dengan lainnya, yakni kijing (jirat), dasarnatau subasmen yang berbentuk persegi panjang dan dengan berbagai variasi kadang-kadang diberi tambahan sudut dan hiasan tangan dalam bentuk simbar (artefiks). Kemudian di atasnya pada sudut puncak bagian utara dan selatan (jirat inti) diletakkan nisan dari batu, kayu atau logam. Nisan ini ada yang dipasang pada bagian kepala saja (utara) atau kedua-duanya, kepala dan kaki, utara dan selatan. Jirat dengan nisan ini kadang-kadang dilengkapi pula dengan bangunan pelindung yang disebut cungkup. Dilihat dari sudut kesenian semata, semua karya seni hias pada makam ini adalah suatu pengungkapan dari seniman berupa gagasan yang dituangkan dalam bentuk garis warna dan irama di mana kesenian adalah pernyataan kebudayaan.

1. Bentuk gabungan sayap-Bucrane.

Bentuk gabungan ini dimaksudkan sebagai bentuk nisan yang memperlihatkan cirri-ciri dimana pola hiasnya memperlihatkan bentuk bucran, yaitu bentuk tanduk kerbau baik yang tampak nyata maupun telah digayakan.

Pada bagian sisi luar dari bucrane- biasanya pada puncak nisan-terdapat hiasan sayap. Pola hias nisan banyak yang berbentuk tanduk maupun sayap. Pada masyarakat tradisional, selain pada makam-makam, bentuk hiasan sayap dan tanduk atau kepala kerbau banyak terdapat bangunanbangunan rumah atau bangunan-bangunan sakral.

2. Bentuk persegi

Bentuk semacam ini adalah rectanguler, di mana pada bagian puncaknya terdapat hiasan yang menjadi mahkota dari nisan tersebut, serta berbentuk kepala kerbau (bucrane) yang sudah

Boechari, 1964, "Prof. Dr. Ng. Poerbatjaraka Ahli Epigrafi Perintis Bangsa Indonesia", dalam Majalah Ilmu-ilmu Sastra Indonesia roor Persembahan Kepada Prof.Dr.R.M.Ng.Poerbatjaraka Berhubungan dengan Ulang Tahun Beliau ke-80 dari Para Murid Beliau. Juni, Jilid Nomor 2. Djakarta: Bhratara. Halaman 119-130.

Abd. Muttalib, , 1986. Makam-Makam Kuna di Sulawesi Sealatan, (Ujungpandang: Laporan hasil penelitian Balai Arkeologi Makassar), h. 6-23

- Muhaeminah. 2001. Situs Makam Kuna Islam di Soppeng, (Makassar: Jurnal Arkeologi "Walennae", Vol.IV, 2001), h. 47

Muhaeminah. 2005. Tinggalan Masa Islam di Barrang Lompo Makassar, Analisis Survei Arkeologi, (Makassar: Jurnal Arkeologi ilennae", Vol.VIII), h. 91 
distilir (digayakan). Secara keseluruhan bentuk bangunan tersebut menyerupai sebuah miniatur candi. Bidang tengah yang merupakan badan nisan berbentuk empat persegi

\section{Bentuk bundar (silendrik)}

Nisan yang berbentuk bundar merupakan bentuk yang paling banyak jumlahnya, tidak hanya di makam-makam kuno tetapi juga diberbagai tempat di Indonesia, nisan berbentuk bundar ini memberikan akar pola bentuk yang telah ada dalam arsitektur pra-Islam yakni lingga (masa Hindu) dan bentuk menhir (masa tradisi megalitik), yang banyak mengalami perkembangan adalah variasi bentuk nisannya, khususnya bentuk pada kakinya dan puncak nisan.

Makam atau kompleks makam dapat dikaji dari berbagai kajian. Ada yang mengkaji makam (terutama nisan makam) berdasarkan tipologi, keletakannya pada suatu bentang alanvtertentu, letak geografis, dan bahan. Nisan makam di Indonesia berdasarkan atas tipologinya menurut Hasan Muarif Ambary (1984) dapat dibagi menjadi tipe Aceh, tipe Demak-Tralaya, tipe BugisMakassar, dan tipe Ternate-Tidore. Berdasarkan atas keletakannya, ada makam yang terletak di dataran rendah dan dataran tinggi. Sementara itu, berdasarkan atas letak geografinya, makam ada yang berada di daerah pesisir atau pantai dan pedalaman.

Makam dapat juga dikaji dari bahan baku penyusunnya. Berdasarkan data makam di Indonesia, bahan makam (terutama nisan) dapat dibagi menjadi: bahan kayu unglen, besi), batu (andesit, kapur, pasir, granit, marmer), dan logam (kuningan, perunggu) (Ambary). Kebanyakan makam terbuat dari bahan kayu dan batu andesit atau batu kali. Tidak banyak bahan baku makam yang terbuat dari batu karang. Makam dari bahan batu karang inilah yang akan kita bahas dalam tulisan ini. Sebagai data diambil contoh makam yang terdapat di kompleks makam orang di Bontoala Makassar.

Penelitian ini merupakan penelitian kualitatif dengan penalaran deskriptif analitis, di mana peneliti menggambarkan secara umum tentang tipologi dan inskripsi makam orang Arab di Bontoala Makassar membandingkannya dengan tipologi dan inskripsi makam secara umum sebagaimana dijelaskan dalam landasan teori.
I Penelitian ini dilaksanakan di Komplek Makam Lajkngiru di Kecamatan Bontoala kota Makassar. Pemilihan lokasi ini sebagai tempat penelitian karena daerah-daerah ini pernah menjadi pusat pemerintahan Kerajaan Gowa Tallo, sehingga konteks makam dapat dikaitkan dengan perkembangan Islam di masa Kerajaan Gowa Tallo, di mana orang Arab yang banyak dimakamkan pada makam tersebut diduga mempunyi peranan penting dalam proses penyebaran Agama Islam pada masa itu.

\section{Peta Lokasi}

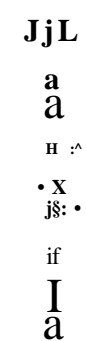

Data yang dihimpun dalam penelitian ini melputi data primer dan data sekunder. Data primer adalah data yang diperoleh secara langsung dari Komplek Makam Lajangiru di Kecamatan Bontoala kota Makassar. Adapun konfirmasi dari lapangan yaitu sebahagian warga masyarakat yang mengetahui sejarah makam yang dimaksud, sedangkan data sekunder ialah data yang diperoleh dari dokumen sejarah masyarakat Sulawesi Selatan, etnografi dan sumber-sumber lain yang mempunyai relevansi dengan penelitian ini.

Untuk memenuhi data yang diperlukan dalam penelitian ini, maka ditempuh beberapa teknik pengumpulan data, yaitu:

1. Penjajagan, yaitu mencari informasiinformasi data yang terkait dengan makam raja-raja Tallo dan melakukan pengamatan langsung di lapangan terhadap obyek yang akan diteliti.

2. survei, yakni pengambilan data dengan cara mengamati langsung makam Lajangiru di Bontoala Makassar. 
;ntasi; pengambilan gambar lokasi ".:an. gambarbentuk-bentuk makam, bentuk- nisan dan inskripsi pada makam secara

\section{- mengungkapkan tipologi makam}

sis morfologis

Satnan pengamatan dalam analisis bentuk ?entuk umum makam dan ragam hiasnya. umum bentuk makam dapat dibagi beberapa bagian, yaitu: jirat/kijing, dan cungkup. Jirat/kijing umumnya :uk segi panjang, trapezium, atau n. sedangkan orientasinya mengarah ke inh utara selatan.

nisan secara umum dapat dibagi menjadi

- rangunan, yaitu kaki, tubuh, bahu, dan

- Bagian kaki dan tubuh nisan dapat hobentuk datar atau runcing; sedangkan bagian a ada yang berbentuk segitiga, segiempat, aau"bulat. Pengukuran pada nisan dilakukan panjang dan lebar, atau diameter dari

- - bagian nisan.

- umum cungkup makam dapat dibagi _:i tiga bagian, yaitu bagian kaki, tubuh dan

Hap. Bagian kaki cungkup ada yang ditinggikan . > ang tidak; sedangkan bagian tubuhnya ang diberi dinding yang lengkap dengan

-.en-komponennya seperti pintu, jendela

$\backslash$ entilasi. Terkadang dinding cungkup hanya

- - sebuah pintu saja, bahkan terkadang tubuh ^ismakup. hanya berupa tiang-tiang penyangga atap it a. Bentuk-bentuk atap cungkup dapat berupa atap tumpang, kubah, atau pelana. Pengukuran . angkup dilakukan terhadap ukuran rangunan cungkup keseluruhan serta unsur-unsur "•i-gunannya.

\section{$\underline{\text { Iualisis }}$ Teknologi}

analisis teknologi makam, variabel-variabel

$1 \mathrm{~g}$ diamati meliputi bahan dan teknik pembuatan/konstruksi. Pada umumnya bahan riku yang digunakan untuk jirat/kijing

." jgunakan bata atau batu, sedangkan untuk - san biasanya menggunakan bahan batu, terakota - i - kayu. Bahan baku yang digunakan untuk ._ngkup umumnya menggunakan bata, batu, atau <olu sedangkan bagian atap biasanya berupa _r-,:eng atau sirap.
Dalam pembuatan jirat dan cungkup dikenal beberapa teknik pembuatan, yaitu teknik tumpuk dengan spesi, teknik tumpuk tanpa spesi, teknik samurig dengan pengait, dan teknik sambung tanpa pengait. Nisan umumnya dibentuk dengan teknis pangkas. Sedangkan dalam pembuatan ragam hias makam dilakukan dengan teknik gores atau teknik pahat.

3. Analisis Inskripsi

Identifikasi aksara antara lain keadaan pahatan aksara, jumlah baris yang dipahatkan pada masing-masing sisi lembaran/lempeng/bidang prasasti(nisan), ukuran aksara, dan pola pemahatannya (berkeliling, memutar, hanya pada satu sisi, pada kedua sisi, atau semua sisi). Selain itu dicatat pula "gaya aksara" atau tipe aksara (persegi, halus, bulat, ramping, tipis, tebal dan sebagainya), posisi aksara miring, tegak, mengidentifikasi bahasa yang digunakan menerjemahkannya dan menjelaskan maknamakananya, kemudian melakukan pembahasan.

Analisis wacana berdasarkan data verbal berupa inskripsi dan data nonverbal dimaksudkan untuk mengetahui sejauh mana data tersebut menunjang informasi historis tentang kedatangan orang Arab dan peranannnya dalam proses penyebaran Islam.

4. Analisis Kontekstual

Variabel-variabel yang dapat dijadikan satuan pengamatan dalam analisis kontekstual meliputi keadaan lingkungan di mana makam didirikan, baik berupa lingkungan fisik maupun bangunan lain yang didirikan di sekitarnya. Dalam analisis kontekstual diharapkan dapat diketahui adanya hirarki kerabat atau hirarki sosial pada sebuah komplek makam. Selain itu dilakukan juga pengukuran jarak antar temuan dan jarak temuan dengan sumber daya alam yang ada di sekitarnya. Pengukuran ini bertujuan untuk mengetahui pola persebaran temuan.

\section{HASIL PENELITIAN DAN PEMBAHASAN}

\section{Gambaran Umum Lokasi Penelitian}

Kota Makasar adalah sebuah kotamadya dan sekaligus ibu kota provinsi Sulawesi Selatan. Kota Makasar secara geografis terletak antara 119 derajat bujur timur dan 5,8 derajat lintang selatan. Wilayah Kota Makasar berbatasan dengan Selat Makassar di sebelah barat, Kabupaten Kepulauan Pangkajene di 
sebelah utara, Kabupaten Maros di sebelah timur dan Kabupaten Gowa di sebelah selatan. Luas wilayah Kota Makasar 175,77 Km2 yang terbagi menjadi empat belas kecamatan.

Kota ini termasuk kota kosmopolis, banyak suku bangsa tinggal di sini. Di kota ini ada suku Makassar, Bugis, Toraja dan Mandar. Di kota ini ada pula komunitas Tionghoa yang cukup besar. ${ }^{6}$ Kota Makassar yang pernah bernama Ujung Pandang adalah wilayah Kerajaan Gowa dan Kerajaan Tallo. Pada mulanya merupakan bandar kecil yang didiami oleh Suku Makassar dan Bugis yang dikenal sebagai pelaut ulung dengan perahu PINISI atau PALARI.

Kerajaan Gowa berdiri kira-kira tahun 1300 Masehi dengan raja yang pertama adalah seorang perempuan bernama tumanurung (1320-1345) yang kawin dengan Karaeng Bayo berasal dari Bonthain yang menurunkan raja-raja Gowa selanjutnya. Pusat Kerajaan Gowa ini terletak diatas bukit Takka'bassia. yang kemudian berubah namanya menjadi Tamalate, tempat ini menjadi pusat Kerajaan Gowa sampai kepada masa pemerintahan Raja Gowa ke-VIII IPakere Tau Tunijallo Ri Passukki (1460-1510). Dalam masa pemerintahan Raja Gowa ke-VI Tunatangka Lopi 1445-1460) terjadi pembagian kerajaan, yaitu Kerajaan Gowa dan Kerajaan Tallo, masing-masing dipegang oleh kedua puteranya yaitu Kerajaan Gowa dipegang oleh Batara Gowa Tuniawanga Ri Paralekkanna sebagai Raja Gowa ke-VII (1460) dan Kerajaan Tallo dipegang oleh Karaeng Loe Ri Sero sebagai Raja Tallo Pertama. Raja Gowa ke-IX Daeng Matanre Karaeng Mangnguntungi yang bergelar Tumapa'risi Kallona kedua kerajaan Gowa dan Tallo disatukan kembali dan diperintah oleh Raja Gowa, dan yang menjadi Mangkubumi adalah Raja Tallo. Kedua kerajaan ini sering disebut Kerajaan Makassar.'

Pembangunan Benteng Somba Opu dari tanah Hat pada tahun 1525 oleh Raja Gowa ke-Ix Tumapa'risi Kallonna (1510-1546). Dalam benteng ini dibangun istana raja Gowa. Makassar (Kerajaan Gowa) menjadi pusat bandar niaga dengan syahbandar adalah Daeng Pammate yang diangkat pada tahun 1538. Sejak itu Makassar menjadi Ibu Negeri, dengan bertitik pusat pada Kota Raja Somba Opu. ${ }^{8}$

Prof. DR. H. A. Mattulada (Aim) dalam bukunya yang berjudul: Menyusuri Jejak Kehadiran Makassar dalam Sejarah menulis sbb: menyusuri kembali jejakjejak kehadiran Makassar sebagai term, dalam lintas sejarah yang dimulai pada abad Nagarakertagama, jaman Patih Gajah Mada di Majapahit, atau sedikit menjangkau kedepannya ketikatenggelamnya Kerajaan Sriwijaya, Singasari dibawah Raja Kertanegara (12541292), maka dapatlah kita mengambil beberapa kesimpulan bahwa konsepsi Makassar atau Mangkasara: itu mengandung sekurang-kurannya 3 macam pengertian, yaitu:

1). Makassar sebagai group etnis, (suku bangsa Indonesia) yang berdiam di sepanjang pesisir selatan jazirah Sulawesi Selatan, yang mempunyai bahasa dan peradaban sendiri yang hidup sampai sekarang.

2). Makassar sebagai sebutan kepada Kerajaan Kembar Gowa Tallo dengan nama Kerajaan atau Kesultanan Makassar, sebagai sebuah kerajaan yang paling berpengaruhi di Sulawesi atau bagian timur Indonesia dalam abad XVI-XVII.

3). Makassar sebagai ibukota kerajaan, bandar niaga yang tumbuh setelah jatuhnya Malaka ke tangan Portugis dalam tahun 1511 dan dijadikannya pusat terdepan kerajaan Makassar yang mewadahi benteng-benteng Somba Opu, Panakkukang dan benteng Ujung Pandang (Jumpandang). ${ }^{10}$

Dengan demikian nama Makassar pada dasarnya sejak lama telah dikenal oleh masyarakat luas baik sebagai suatu daerah maupun sebagai salah satu suku bangsa yang telah eksis dalam pertarungan budaya dan politik nusantara. Kebesaran nama Makassar dan letak strategisnya merupakan suatu potensi untuk menjadikan Makassar sebagai kota dunia sebagaimana pencapaian yang pernah dicapai pada masa lalu yang banyak didengungkan dalam sejarah.

Sumber Data: Sulawesi Selatan Dalam Angka 2007 (01-7-2007) BPS Provinsi Sulawesi Selatan

Ahmad M. Sewang. 2005. Islamisasi Kerjaan.Gowa, (Abad XVI sampai Abad XVII), Edisi kedua, Jakarta: Yayasan Obor Indonesia: 2005, h. 21-22

Edward L. Poelinggomang dan Suriadi Mappangara. 2003. Sejarah Perkembangan Kerajaan-kerajan di Sulawesi Selatan, Balitbangda Makassar: h. 48

Mattulada, 1982. Menyusuri Jejak Kehadiran Makassar dalam Sejarah, 1510-1700, Ujung Pandang, Bhakti Baru: h. 61

${ }^{10}$ Ibid, h. 61 


\section{- Arkeologis Komplek Makam Lajangiru}

N ma kompleks makam "Lajangiru" diambil dari pfar seorang yang bernama Abd.Madjid Lajangiru yaitu

- tokoh masyarakat yang berprofesi sebagai

- -ar.adan berjaya pada kurun masa 1910 hingga

M. Lajangiru berasal dari bangsawan Wajo

ia adalah seorang pengusaha kaya yang

- tarkannya menjadi pemilik tanah-tanah yang luas

- - adian mempunyai pengaruh bagi masyarakat

"z-; a. Diceritakan bahwa salah seorang saudara

- aan ayahnya dinikahi oleh seorang sayyid yang

." - dari Hadramawt untuk berdakwah menyebarkan $\boldsymbol{s} \& \boldsymbol{m}$ di Makassar. Ketika sayyid itu meninggal,

- -"-•• a dimakamkan di atas tanah milik Lajangiru.

- enjadi tonggak awal dimakamkannya orang-or-a'r lainnya yang kebetulan wafat pada masa itu,

-' " kemudian lahan ini dikenal oleh masyarakat sesasai makam orang Arab.

Pemberian nama kompleks makam Lajangiru

- -an pada masa pemerintahan Walikota Makassar g Patompo, yang awalnya berencana menggusur lan tersebut untuk dijadikan sebagai sarana namun hal ini ditolak oleh keluarga Lajangiru, bersama masyarakat sekitar memperjuangkan okasi itu dapat dijadikan sebagai salah peninggalan arah $\backslash$ ang kemudian disahkan menjadi cagar budaya - Departemen Pariwisata dengan nama Kompleks -a.angina, hal ini karena Abd. Madjid Lajangiru sendiri -_a dimakamkan dalam lokasi tersebut. Meskipun lan masyarakat sekitar masih sering menyebut at itu dengan nama Makam Arab.

$$
4
$$

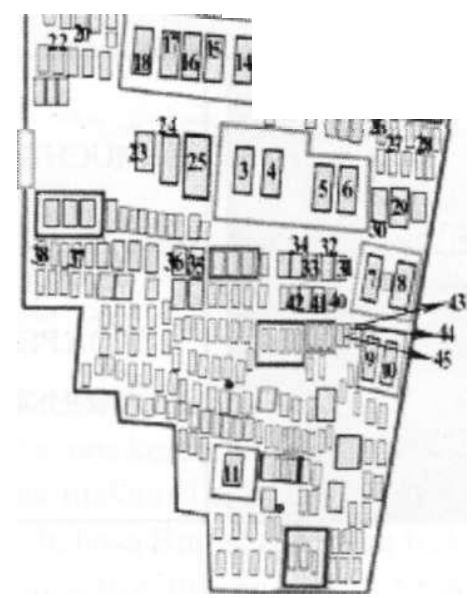

Secara umum keadaan jumlah makam komp-Ieks Lajangiru dapat dilihat dalam gambar di atas, terdapat sebanyak 233 buah yang pada umumnya berbentuk jirat dan nisan dan ada pula beberapa yang hanya nisan saja. Dari 233 makam tersebut ditemukan adanya makam yang berusia 50 tahun ke atas sebanyak 45 buah makam, selanjutnya pembacaan inskripsi dilakukan terhadap tujuh buah makam.

Dalam kompleks makam Lajangiru ini pula terdapat lima makam besar, salah satunya merupakan bangunan berbentuk persegi yang minimalis menyerupai pintu gerbang, sedangkan empat dari bangunan makam tersebut berbentuk kubah masjid. Masyarakat setempat menyebutnya dengan nama kobbang yang serupa dengan bentuk makam syekh Yusuf.

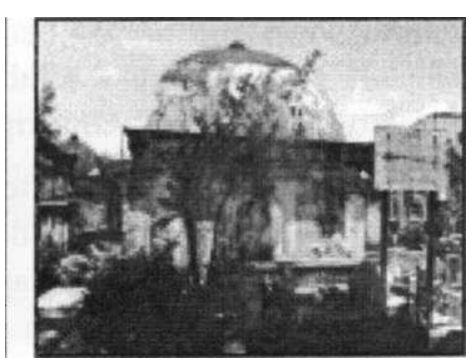

Di dalam kobbang (banguan makam) ini terdapat masing-masing dua kuburan yang berukuran besar dengan jirat berbentuk segi empat panjang dan nisan yang berbentuk persegi maupun ada yang benbentuk bundar. i
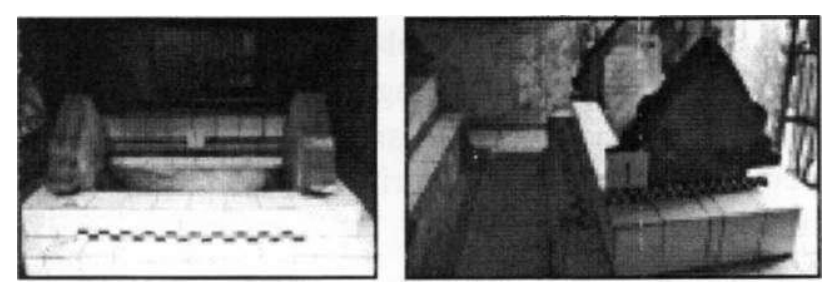

Tampak jelas bahwa makam ini telah diper-baharui dan dibuat dengan menggunakan kramik modern. Namun keaslian makam ini terungkap jelas pada prasasti yang dilekatkan pada dindign nisannya.
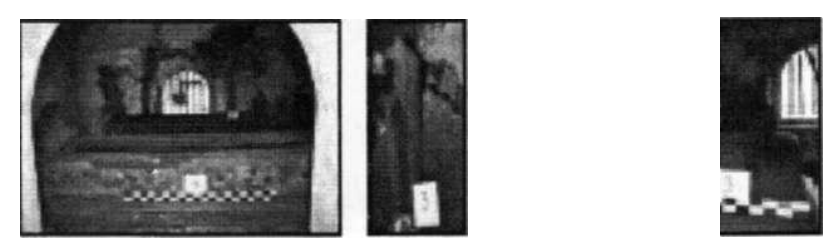

Makam ini terbuat dari batu andesit dengan ukiran sulur-sulur daun pada dinding jiran dan nisan. Pada salah satu dindingjiratterdapat sebuah inskripsi. 

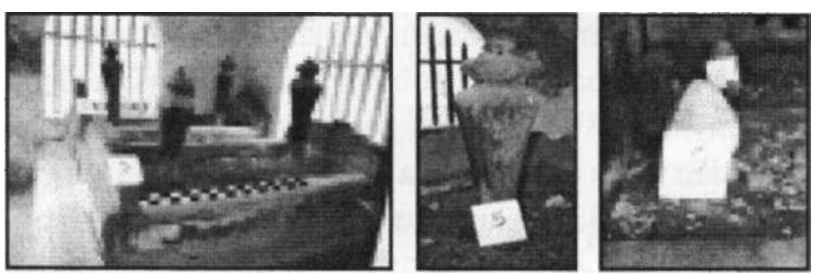

Makam yang nisannya terbuat dari kayu berbentuk bulat panjang dengan kepala yang menyerupai piala atau mahkota raja.
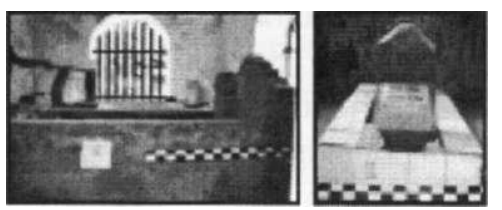

"7mm

Makam no. 7 dan 8 berada dalam satu kubah dengan jirat dan nisan yang terbuat dari batu andesit, pada nisannya terdapat inskripsi berhuruf Arab. Makam no. 11 tampak telah diperbaharui kecuali nisannya yang terdapat inskripsi berbahas Indonesia.

Tipe-tipe makam yang terdapat dalam kobbang tersebut di atas sama halnya dengan makam yang ada di luar kobbang. Sehingga dapat disimpulkan bahwa secara umum tipe makam yang terdapat dalam kompleks makam Lajangiru ini mempunyai satu konsep yang sama, terdiri dari jirat dan nisan, dan dengan tata letak Utara-Selatan sebagaimana lazimnya kuburan lain yang ada di Sulawesi Selatan.

\section{Klasifikasi dan Isi Inskripsi pada Makam} Lajangiru

Berdasarkan data tersebut di atas dapat diklasifikasikan jenis inskripsi yang ada dalam beberapa hal yaitu; isi inskripsi, bahasa yang digunakan, dan bahan penulisan. Dari segi materi inskripsi terdapat tiga macampenulisan:

1. Penulisan Nama dan Waktu Wafat

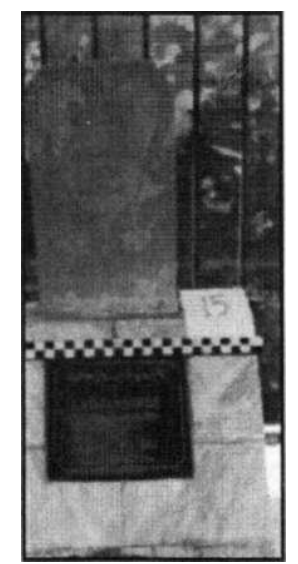

Ladjangiroe

H.Abd. Madjid

Wafat

22 Mar 1931

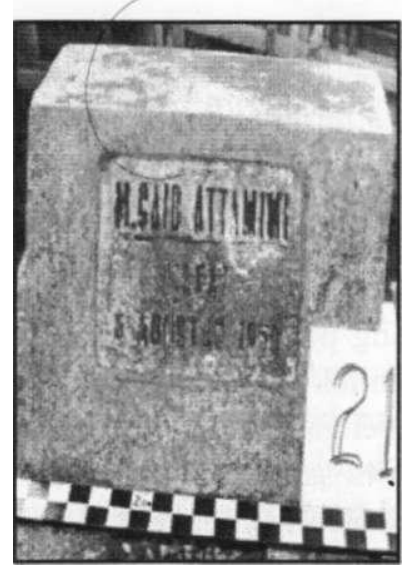

M.SAID ATTAMIMI

WAFAT

5 AGUSTUS 1950

IME PARANAKENG

NAMATE KEMISI

16 BULAN MAUDU 1340

18111921 UMURUNA

78TAUNG

2. Penulisan Kaja Tunjuk, Nama dan Waktu Wafat

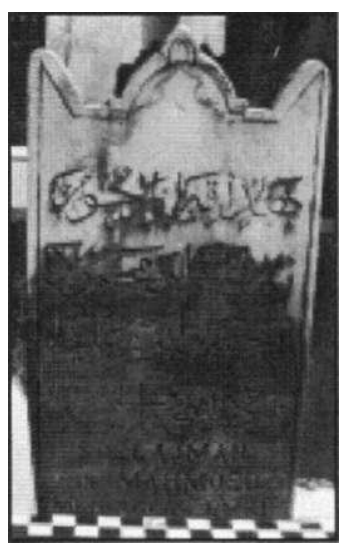

$t \mathrm{i}^{*} \mathrm{j}^{\mathrm{J}} j A_{\mathrm{Ij}} *$

SOELAJMAN

BIN MAHMOED

MENINGGAL $1 / 1 / 21$

3. Penulisan Nama, Waktu Wafat dan Keterangan Wafatnya

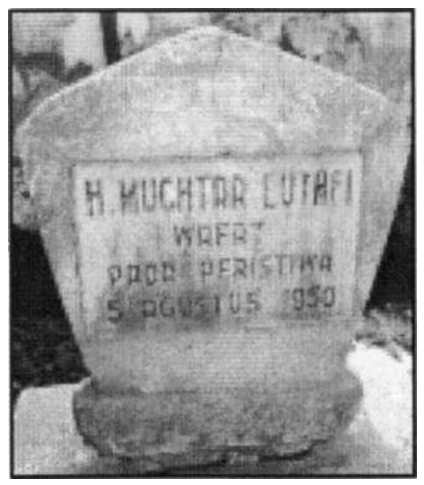

H.MUCHTAR LUTHFI

WAFAT

PADA PERISTIWA

5 AGUSTUS 1950 

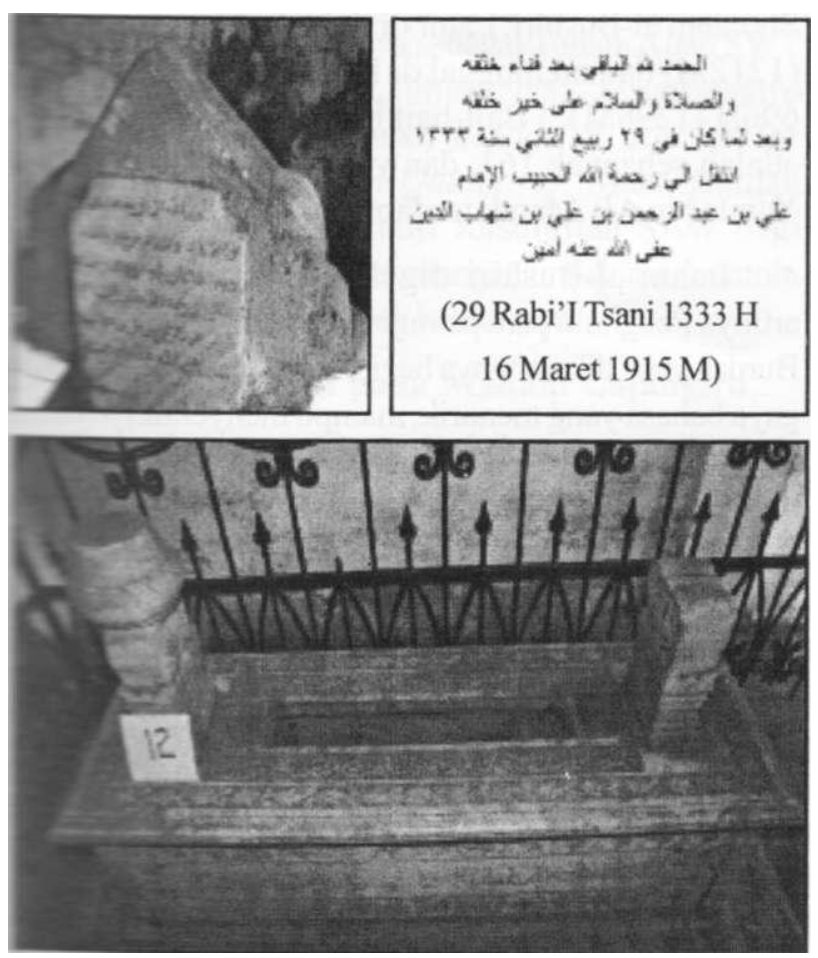

$\mathbf{a}^{\wedge} \mathbf{u f t}$

$\bullet V^{\prime \prime \prime}$

-: >»-' ii-Tr'- $\left.J^{*} * * *\right)$ UAj JU.J Jm» j'liv"

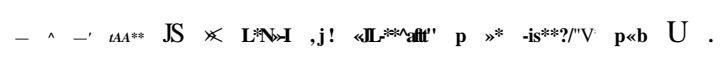

$\mathrm{I}^{* * ? "} \quad-, \cdot \mathrm{j} \mathrm{T} \quad \mathbf{i j} \mathbf{j}^{* \prime}$

$t *_{\mathrm{r}}$ "»"*^ J JS*«

>.skripsi tersebut ditulis pada nisan kayu dan batu a:au berupa keramik. Secara bahasa penulisan - atnpsi pada makam Lajangiru ini digunakan tiga a c a s yaitu; bahasa Bugis, Arab dan Indonesia. Dari - <r -ruhan inskripsi, tulisan bahasa Arab merupakan yang terbanyak sebagaimana tampak dalam bait doa pada makam Habib Imam Ali bin Abdurrahman bin Ali bin Syihabuddin dan syair shalawat burdah yang terdapat pada makam Yunus bin Ali Afandi.

\section{Makna dan Fungsi Inskripsi pada Makam Lajangiru}

Tujuan dari penelitian bidang Arkeologi Epigrafi bahasa Arab. Namun sebuah inskripsi terlalu singkat dan sukar dipahami maknanya sehingga sangat dibutuhkan penelitian yang teliti dengan membandingkannya dengan sumber-sumber arkeologi dan naskah sejarah.

\section{Makna Inskripsi pada Makam Lajangiru}

Temuan inskripsi pada kompleks makam Lajangiru menunjukkan cirikhas tersendiri di mana terdapat inskripsi yang cukup panjang memenuhi badan jirat dan nisan makam. Inskripsi ini tertulis di atas makam seorang pendatang dari Turki Yunus bin Ali Afandi, yang berisi nama dan qasidah burdah secara lengkap bertuliskan sebagai berikut:

\author{
I adalah kubur almarhum \\ Yunus bin Ali Afandi \\ Tahun 1335 H/1916 M
}

\section{Alfaatihah}

Ditujukan kepada ruh Yunus Bin Ali Afandi Semoga Allah merahmatinya 1335

$$
\mathrm{JU}-\quad \mathrm{jL} \ll \mathrm{i}>-\quad .5 \backslash \mathrm{j}
$$

Tiada tuhan selain Allah dan Muhammad adalah Rasul Allah

Ini adalah karunia dari Tuhanku Abubakar, Umar, Utsman, Ali 
Ya Allah, limpahkanlah salawat dan keselamatan selalu dan selamanya kepada kekasih-Mu makhluk yang terbaik dari segalanya.

Wahai dirijanganlah engkau berputus asa, dari dosa sungguhpun ia besar, Kerana sesungguhnya dosadosa besar itu dibandingkan dengan Keampunan Allahadalah sangat kecil

Semoga rahmat Allah Rabbi Ketika dibagi bagi Datang dalam pembagian Sesuai dengan nilai kedurhakaan

Ya Allah jadikanlah harapan ku Tak berbeda dengan apa yang ada disisimu Dan jadikanlah keyakinanku tiada putus putusnya kepada-Mu

$r m \mathrm{~J}^{*}>\gg \mathrm{Vi} \ll \mathrm{a} ? \mathrm{fj} . \mathrm{i} \wedge 4 \mathrm{~J}$ o| jgjUli j J J U . UWu

Ya Allah kasihanilah hamba $\mathrm{Mu}$ ini Dalam dunia dan akhirat nanti Sesungguhnya ia punya kesebaran ketika bencana menimpa datang tak tahan

Ya Allah curahkan awan ShalawatMu Abadi tak terbatas Kepadajunjungan Nabi-Mu Bagai hujan mengalir deras

Juga keluarga dan Shahabatnya Kemudian para

Tabi'in dan pengikutnya Mereka ahli taqwa dan kesucian Bersifat penyantun dan dermawan

Selagi angin timur masih mendorongkan dahandahan pohon Ban Dan selagi pengembala unta

Senangkan unta dengan suara merdu

Qasidah burdah ialah bait-bait syair indah yang memuji Rasulullah SAW dan perjuangan Baginda, keluarga dan para sahabat. Ia adalah terjemahan perasaan cinta dan kasih sayang yang mendalam terhadap Rasulullah SAW. Menurut sejarah, qasidah burdah dikarang oleh Imam al-Bushiri atau nama penuhnya Muhammad bin Said bin Hamad bin As-
Shonhaji al-Bushiri. Lahjf di Bahtim, Mesir pada $608 \mathrm{H}$ (1212M) dan meninggal di Iskandariyah, Mesir pada 696H (1296M)." Bait-bait burdah yang dikarangnya adalah sebanyak 161, dan yang tertulis pada makam Yunus bin Ali Afandi terdapat 8 bait'.

Imam al-Bushiri digelar "Sayyidul Muddah" artinya Penghulu para pe'rnuji Rasulullah SAW. Bait-bait Burdah yang dikarangnya'begitu indah dan menggunakan gaya bahasa yang menarik, mampu menyentuhjiwa dan mengalirkan air mata orang yang membacanya. Lebih utama, kecintaan kepada Rasulullah SAW semakin mendalam, seiring dengan semangat untuk mengikut sunnah dan perjuangan Baginda SAW.

Semuanya bermula apabila Imam al-Bushiri ditimpa penyakit lumpuh sebelah badan. Berbagai cara rawatan diusahakan namun penyakit lumpuhnya tidak juga sembuh. Para doktor yang merawatnya pun telah berputus asa untuk mengubatinya.

Maka dalam keadaan keuzuran itu, datanglah ilham dalam hatinya untuk mengarang sebuah qasidah puji-pujian terhadap Rasulullah SAW. Rupanya badan yang lemah longlai itu masih lagi memiliki hati yang sangat cergas dan ingatan yang sangat tajam dan keazaman yang kuat.

Maka dengan hati yang dipenuhi kasih sayang dan kecintaan kepada Baginda SAW, al-Imam melakarkan satu demi satu qasidahnya. Satu bait demi satu bait, satu rangkap demi satu rangkap sehingga qasidah diSelesaikan denganjumlah 161 bait. Beliau berharap dengan berkat memuji Baginda, penyakitnya akan disembuhkan Allah SWT.

Diriwayatkan selepas selesai menulis, beliau tertidur dan bermimpi berjumpa Rasulullah SAW. Baginda datang menziarahi beliau yang sedang sakit, lalu Baginda menyapu tangannya yang mulia itu di atas badan Imam al-Bushiri dan menyelimutkannya dengan sehelai selendang (burdah).

Setelah terjaga, didapati penyakit lumpuhnya sembuh. Badan beliau seolah-olah tidak pernah ditimpa penyakit lumpuh. Maka dengan peristiwa ini beliau menamakan qasidah dikarangnya "Burdah". Adajuga riwayat lain yang menyebutkan bahawa Imam alBushiri mendapati "Burdah" atau selendang tersebut ada di atas badannya apabila beliau terjaga dari tidurnya.

Para ulama sepakat bahawa puji-pujian ke atas Rasulullah SAW adalah amalanterpuji, asalkan ia tidak 
$\sim t \backslash$ ampaui batas seperti orang Kristian memuj i Nabi Isa hingga menyatakannya sebagai Tuhan. Allah SWT -ga telah memuj i Baginda, firman-Nya: "Sesungguhnya i'ngkau (wahai Muhammad) berada di atas akhlak - sng sangat agung. " (al-Qalam: 4). Maka Burdah Bialah satu kaedah memuji Rasulullah SAW bagi C-.anam kecintaan dan semangat untuk mencontohi r-aginda dalam semua aspek kehidupan.

\section{'- Fungsi Inskripsi pada Makam Lajangiru}

Pada dasarnya fungsi inskripsi yang ada pada rakam umumnya dimaksudkan sebagai tanda atau - amat berupa nama dan tanggal wafatnya orang yang : - akamkan di bawahnya. Namun adanya temuan data :aaa makam Lajangiru yang memunculkan berbagai f.is materi inskripsi yang tidak hanya mengandung :i-na dan tanggal kewafatan saja, bahkan ditemukan aianya inskripsi panjang yang berisi doa-doa dan - aaw at yang ditulis dengan khat indah, menunjukkan rshwa tujuan dan fungsi inskripsi pada makam tersebut * ->an hanya berhenti pada sekedar tanda atau alamat •. a. melainkan inskripsi tersebut dapat dijadikan sebagai imgsi syiar Islam, yaitu informasi-informasi tentang -:rak penyebaran ajaran agama Islam pada masa lalu.

Inskripsi tersebut juga dimaksudkan sebagai pelipur an. penghibur dan penguat jiwa bagi keluarga yang $\wedge$ rulangan salah satu anggotakeluarganya yang tercinta. $Z^{\prime}$. mana disebutkan bahwa inskripsi berupa qasidah yjrdah tersebut dapat memberikan kekuatan jjwa dan C:entraman hati bagi orang yang membacanya.

Inskripsi tersebut dijadikan sebagai fungsi syiar slam. Sy/aryangdimaksud disini adalah sebagai tanda iziu lambang keislaman. Bahwa inskripsi qasidah turdah ini memberitakan kepada orang yang e.:hatnya, membacanya dan mengerti artinya bahwa adalah tanda keislaman orang yang dimakamkan di aa amnya, yang dengannya pembaca tersebut dapat $\sim:^{\wedge}$.berikan respon positif atau negatif terhadap isi izri pesan yang dibacanya itu.

ifkripsi Qasidah Burdah sebagai Refleksi ^ranan Yunus bin AH Afandi dalam Masyarakat >lam pada Masa Hidupnya

Ide penulisan qasidah burdah yang disandingkan :engan Yunus bin Ali Afandi pada prinsipnya lahir atas aaiar pertimbangan logis dan keterkaitan yang erat irtara keduanya. Persandingan ini menggambarkan cbuah fakta bahwa Yunus bin Ali Afandi adalah -ang yang cinta pada Nabi Muhammad SAW. •;»aligus sebagai pengamal ajaran-ajarannya. Kedaargannya dari pusat dunia Islam kemudian mene- gaskan salah satu bukti cintanya kepada Nabi adalah dengan menyampaikan ajaran agama Islam kepada masyarakat Makassar. Hal ini sesuai dengan penuturan masyarakat sekitar bahwa Yunus bin Ali Afandi adalah salah satu tokoh masyarakat muslim yang banyak membantu dalam pengembangan ajaran Islam pada masanya.

Dalam catatan sejarah kerajaan Gowa tampak bahwa Yunus bin Ali Afandi hidup dalam masa pemerintahan Raja Gowa, yaitu I Makkulau Daeng Serang Karaeng Lembangparang Sultan Husain Tuminang ri Bundu'na, memerintah sejak tanggal 18 Mei 1895, dimahkotai di Makassar pada tanggal 5 Desember 1895. Ia melakukan perlawanan terhadap Hindia Belanda pada tanggal 19 Oktober 1905 dan diberhentikan dengan paksa oleh Hindia Belanda.pada 13 April 1906. Ia meninggal akibat jatuh di Bundukma, dekat Enrekang pada tanggal 25 Desember 1906

\section{PENUTUP}

\section{Kesimpulan}

Bentuk makam yang terbuat dari batu padat putih dan inskripsi (tulisan Arab qasidah burdah) yang terukir indah pada makam Yunus bin Ali Afandi memberi makna yang jelas akan keberadaan pemiliknya, yaitu seorang muslim yang dihormati dan ditokohkan oleh masyarakat, dan ketokohan tersebut diyakini tumbuh akibat adanya peran Yunus bin Ali Afandi sebagai tokoh masyarakat, pecinta nabi Muhammad saw. dan sebagai penybar ajaran agama Islam pada masanya. Inskripsi tersebut juga menggambarkan adanya upaya untuk memungsikan makamnya sebagai tanda syiar Islam atau sebagai media untuk menyampaikan pesan cinta kepada Nabi Muhammad saw. dalam bentuk inskripsi qasidah burdah.

Berdasarkan fakta sejarah bahwa Yunus bin Ali Afandi ini tidak hanya sebagai tokoh penyebar ajaran agama Islam, akan tetapi juga sebagai tokoh masyarakat baik di kalangan masyarakat Arab maupun bagi masyarakat Makassar Sulawesi Selatan khususnya yang beragama Islam. Makam ini sekaligus memberi bukti bahwa penyebaran Agama Islam di Sulawesi Selatan dibawa langsung oleh orang-orang Arab yang datang atau berguru dari Hadramawt. Sehingga dengan bukti ini diharapkan kepada pemuda Islam agar terinspirasi dan berupaya mengikuti perjuangan mereka yang begitu gigih dalam menyebarkan Agama Islam. 


\section{Saran}

Makam Yunus bin Ali Afandi dan makam-makam tokoh penyebar Agama Islam lainnya yang di makamkam dalam kompleks makam Lajangiru Bontoala Makassar diharapkan agar dilestarikan dan dijadikan sebagai lokasi wisata spiritual bagi masyarakatmuslim di Makassar Sulawesi Selatan, bagi masyarakat Indonesia dan bahkan bagi masyarakat luar negeri.

Hendaknya dilakukan penelitian lebih lanjut untuk membaca inskripsi makam yang belum sempat terbaca, yaitu makam-makam yang inskripsinya sudah semakin usang dan sulit dibaca sehingga membutuhkan teknik yang lebih baik dan waktu yang lebih lama dalam menelitinya.

\section{Ucapan Terima Kasih}

Terima kasih kepada para pemateri, instruktur dan panitia serta alumnus Diklat Arkeologi Badan Litbang dan Diklat Kementerian Agama RI. Pengelola makam Lajangiru Bontoala Makassar serta semua pihak yang telah membantu memberikan informasi demi terlaksananya penelitian ini.

\section{DAFTARPUSTAKA}

Ambary. Hasan Muarif. 2001. Menemukan Peradaban Jejak Arkeologis dan Historis Islam Indonesia, Cet. II Logos, Jakarta, Wacana Ilmu.

Ahmad. Abd.Kadir, Editor. 2004. Masuknya Islam di Sulawesi Selatan dan Sulawesi Tenggara, Balai Penelitian dan Pengembangan Agama Makassar, Makassar.

Boechari. 1964. "Prof. Dr. Ng. Poerbatjaraka Ahli Epigrafi Perintis Bangsa Indonesia", dalam Majalah Ilmu-ilmu Sastra Indonesia. Nomor Persembahan Kepada Prof. Dr. R. M. Ng.Poerbatjaraka Berhubungan dengan Ulang Tahun Beliau ke-80 dari Para Murid Beliau. Juni, Jilid II, Nomor 2. Djakarta: Bhratara. Halaman 119-130.

Chandrasasmita, Uka. 2000. Penelitian Arkeologi Islam di Indonesia dari Masa ke Masa, Cet. 1-Kudus: Menara Kudus.

Claude Guillot dan Ludvik Kalus. 2008. Inskripsi Islam Tertua di Indonesia, Penerbit: Kepustakaan Populer Gramedia.

Damais, Louis-Charles. 1995. Epigrafi dan sejarah Nusantara: pilihan karangan. Jakarta: Pusat Penelitian Arkeologi Nasional, Ecole Francaise d'Extreme-Orient, xvi + 362 pp

Edward L. Poelinggomang dan Suriadi Mappangara. 2003. Sejarah Perkembangan Kerajaan-kerajan di Sulawesi Selatan, Balitbangda Makassar.
Mattulada. 1982. Menyusuri Jejak Kehadiran Makassar dalam Sejarah, 1510-1700, Ujung Pandang: Bhakti Bare.

Muttalib, Abd. 1986. Makam-Makam Kuna di Sulawesi Sealatan, (Ujungpandang: Laporan hasil penelitian Balai Arkeologi Makassar), h. 6-23 V

Muhaeminah. 2001. Situs Makam Kuna Islam di Soppeng, Makassar: Jurnal Arkeologi "Walennae", Vol. IV.

2005. Tinggalan Masa Islam di Barrang Lompo Makassar, Analisis Sqrvei Arkeologi, (Makassar: Jurnal Arkeologi "Walennae"" Vol.VIII

Patunru,AbdurrazakDeang. 1983. Sejarah Gowa, Ujuang Pandang: Yayasan Kebudayaan Sulawesi Selatan.

Pusat Penelitian dan Pengembangan Arkeologi Nasional. 2008 Metode Penelitian Arkeologi, Jakarta: Cetakan Kedua.

Sewang, Ahmad M. 2005. Islamisasi Kerjaan Gowa, (AbadXVI sampai AbadXVII), Edisi kedua, Yayasan Obor Indonesia

http://al-aziziyah.com/santri-menulis/74-santri-menulis/101qasidah-burdah.html 21 September 2010 